OPEN ACCESS

Edited by:

Xiaoli Wei,

University of California, San Diego,

United States

Reviewed by:

Xiaoyi Wang

University of Connecticut,

United States

Xiaoli Liu,

Technical University of

Denmark, Denmark

*Correspondence:

Rong Gui

aguirong@163.com

Xinmin Nie

niexinmin7440@sina.com

Specialty section:

This article was submitted to Nanoscience,

a section of the journal

Frontiers in Chemistry

Received: 31 January 2020

Accepted: 09 April 2020

Published: 07 May 2020

Citation:

Shang Y, Wang $Q$, Li J, Zhao Q, Huang $X$, Dong H, Liu H, Gui R and

Nie $X(2020)$

Platelet-Membrane-Camouflaged

Zirconia Nanoparticles Inhibit the Invasion and Metastasis of Hela Cells.

Front. Chem. 8:377.

doi: 10.3389/fchem.2020.00377

\section{Platelet-Membrane-Camouflaged Zirconia Nanoparticles Inhibit the Invasion and Metastasis of Hela Cells}

\author{
Yinghui Shang ${ }^{1}$, Qinghai Wang ${ }^{2}$, Jian $\mathrm{Li}^{1}$, Qiangqiang Zhao ${ }^{1}$, Xueyuan Huang ${ }^{1}$, \\ Hang Dong ${ }^{1}$, Haiting Liu ${ }^{1}$, Rong Gui ${ }^{1 *}$ and Xinmin Nie ${ }^{3 *}$ \\ ${ }^{1}$ Department of Blood Transfusion, the Third Xiangya Hospital, Central South University, Changsha, China, ${ }^{2}$ Department of \\ Cardiology, the Second Hospital of Shandong University, Jinan, China, ${ }^{3}$ Clinical Laboratory of the Third Xiangya Hospital, \\ Central South University, Changsha, China
}

Zirconia nanoparticles (ZrO2 NPs) are widely applied in the field of biomedicine. In this study, we constructed a nanoplatform of $\mathrm{ZrO} 2 \mathrm{NPs}$ coated with a platelet membrane (PLTm), named PLT@ZrO2. PLTm nanovesicles camouflage ZrO2 NPs, prevent nanoparticles from being cleared by macrophage, and target tumor sites. Compared to ZrO2 alone, PLT@ZrO2 is better at inhibiting the invasion and metastasis of Hela cells in vitro and in vivo. In vitro, PLT@ZrO2 inhibited the growth and proliferation of Hela cells. Scratch-wound healing recovery assay demonstrated that PLT@ZrO2 inhibited Hela cells migration. Transwell migration and invasion assays showed that PLT@ZrO2 inhibited Hela cells migration and invasion. In vivo, PLT@ZrO2 inhibited the tumor growth of Xenograft mice and inhibited the lung and liver metastasis of Hela cells. Immunofluorescence and Western blotting results showed that anti-metastasis protein (E-cadherin) was upregulated and pro-metastasis proteins ( $\mathrm{N}$-cadherin, Smad4, Vimentin, E-cadherin, $\beta$-catenin, Fibronectin, Snail, Slug, MMP2, Smad2) were downregulated. Our study indicated that PLT@ZrO2 significantly inhibits tumor growth, invasion, and metastasis.

Keywords: platelet membrane, zirconia, invasion, metastasis, anticancer

\section{INTRODUCTION}

Zirconium oxide nanoparticles ( $\mathrm{ZrO} 2 \mathrm{NPs}$ ) possess many good electrochemical properties, such as non-toxicity, thermal stability, wide band gap, and excellent electrical and surface performances (Yang et al., 2007). ZrO2-based biosensors for oral cancer drug detection (Kumar et al., 2016), and electrochemical sensors for anticancer drugs by $\mathrm{ZrO} 2$ NPs-decorated nanocomposite (Venu et al., 2018), have also been implemented. Sulphated zirconia nanoparticles have been studied in anticancer applications (Mftah et al., 2015) and sulfated zirconia nanoparticles doped by ironmanganese are cytotoxic to cancer cells (Al-Fahdawi et al., 2015). Moreover, ZrO2 NPs have exhibited cytotoxicity against human carcinoma cell lines (Balaji et al., 2017), but their antitumor activity and mechanism has not been explored thoroughly. 
Current studies have indicated that tumor metastasis is facilitated by blood platelets (PLTs) (Karpatkin and Pearlstein, 1981; Gasic, 1984; Tanaka et al., 1986; Chen et al., 1992; Honn and Tang, 1992a,b; Nieswandt et al., 1999), and platelets and tumor cells are bound by P-selectin and the CD44 receptor (Borsig et al., 2001; Hu et al., 2015a) with capture based on structure (Sabrkhany et al., 2018). Previous studies have indicated that platelet-membrane-camouflaged black phosphorus quantum dots could target tumor sites (Shang et al., 2019), but it has not been studied whether platelet-membrane-camouflaged nanoparticles can target tumor metastasis.

Although surgical techniques and chemotherapy regimens have improved, metastasis remains a serious barrier to the effective treatment for patients with cervical cancer ( $\mathrm{Li}$ et al., 2016), and the prognosis of patients suffered from metastatic cervical cancer is poor (Peng et al., 2016). To address these challenges, we constructed platelet-membranecamouflaged ZrO2 NPs (PLT@ZrO2) to investigate targeting of metastatic tumors and anti-metastasis activity.

\section{MATERIALS AND METHODS}

\section{Materials}

Zirconia nanoparticles (XF101) were prepared by the XFNANO Materials Tech Co., Ltd. (China). Yeasen Biotechnology (China) provided Cy5, Rhodamine B (RhB), Hoechst 33342, and distearyl phosphatidyl ethanolamine-fluorescein isothiocyanate (DSPEFITC). Solarbio (China) provided dialysis membranes $(2 \mathrm{kD})$. Whatman (USA) provided polycarbonate porous membrane syringe filters $(200 \mathrm{~nm})$. Life Technologies (USA) provided RPMI-1640, Dulbecco's modified Eagle medium (DMEM) (high glucose), fetal bovine serum (FBS), and trypsin EDTA. Servicebio Technology Co., Ltd. (China) supplied One Step TUNEL Apoptosis Assay Kit, DAPI, Calcein-AM, crystal violet, hematoxylin and eosin (HE), anti-N-cadherin, anti-Vimentin, anti-E-cadherin, anti- $\beta$-catenin, anti-Fibronectin, anti-Snail, anti-Smad4, anti-Slug, anti-MMP2, anti-Smad2, anti- $\beta$-actin, anti-GAPDH antibodies, horseradish peroxidase (HRP) goat anti-rabbit IgG secondary antibodies, cy3 goat anti-IgG and FITC goat anti-IgG secondary antibodies, and a prestained protein ladder.

\section{Cells and Animals}

The Cancer Research Institute of Central South University gifted the Hela human cervical cancer cell line. The Hela cells were cultured in DMEM (high glucose) containing 10\% FBS. RAW264.7 macrophages were cultured in RPMI-1640 medium containing $10 \%$ FBS. All cells were incubated at $37^{\circ} \mathrm{C}$ in a $5 \%$ $\mathrm{CO}_{2}$ incubator. Hunan SJA Laboratory Animal Co., Ltd provided 6 week old female Balb/c nude mice.

\section{PLTm Vesicles Preparation}

PLTs were obtained by centrifugation (1,500 rpm, $5 \mathrm{~min}$ ) and double washing with PBS of whole blood from female Balb/c nude mice. PLTm vesicles of $\sim 150 \mathrm{~nm}$ were prepared by repeated freezing (at $-80^{\circ} \mathrm{C}, 2 \mathrm{~h}$ ) and thawing (at $37^{\circ} \mathrm{C}, 10 \mathrm{~min}$ ) PLTs, and ultrasonic treatment ( $2 \mathrm{~min}, 42 \mathrm{kHZ}, 100 \mathrm{~W}$ ) of PLTs (Hu et al., 2015b).

\section{Construction of PLT@ZrO2}

Ultrasonic treatment ( $5 \mathrm{~min}, 42 \mathrm{k} \mathrm{Hz}, 100 \mathrm{~W}$ ) of $\mathrm{ZrO} 2 \mathrm{NPs}$ with an equal volume of PLTm vesicles promoted camouflage of the nanoparticles. After filtration with porous syringe filters $(200 \mathrm{~nm})$ and centrifugation $(2,500 \mathrm{rpm}, 10 \mathrm{~min})$, PLTm vesicles which did not camouflage ZrO2 NPs were settled out and the PLT@ $\mathrm{ZrO} 2$ were obtained. Generally, $300 \mu \mathrm{L} \mathrm{ZrO} 2 \mathrm{NPs}(50 \mu \mathrm{g} / \mathrm{mL})$ were mixed with $300 \mu \mathrm{L}$ PLTm vesicles to pr2Eepare 300 $\mu \mathrm{L}$ PLT@ZrO2.

\section{Characterization of PLT@ZrO2}

A transmission electron microscope (TEM) (Tecnai G2 Spirit, FEI, USA) was used to check the morphology and size of PLT@ZrO2. We could observe the size of the nanoparticles as well as identify whether the nanoparticles were encapsulated into PLTm vesicles. A silicon chip dipped in anhydrous ethanol containing PLT@ZrO2 was examined with atomic force microscopy (AFM) (MFP-3D-S, Asylum Research, USA) to detect the heights of nanoparticles. Zetasizer Nano ZS (Malvern Nano series, Malvern, U.K.) was used to measure the particle sizes and surface charges. UV/vis spectroscopy (ScanDrop, Analytik Jena, Germany) was applied to detect the absorbance of PLT@ZrO2.

\section{Cell Viability of Hela Cells Assessed Through Crystal Violet Staining}

Hela cells were inoculated into $35 \mathrm{~mm}$ dishes $\left(2 \times 10^{5} / \mathrm{dish}\right)$. After $24 \mathrm{~h}$, the cells were treated with new medium, ZrO2, PLTm vesicles or PLT@ZrO2. The concentration of ZrO2 NPs used in this study was $50 \mu \mathrm{g} / \mathrm{mL}$. After $24 \mathrm{~h}$, crystal violet $300 \mu \mathrm{l}$ was added into each well and then washed with PBS to assess the viable cells.

\section{Scratch-Wound Healing Recovery Assays}

Hela cells were seeded in a 6 -well plate $\left(1 \times 10^{5} /\right.$ well $)$. After $24 \mathrm{~h}$, the culture medium was removed, straight incisions were made by a $10 \mu \mathrm{l}$ pipette tip, and then cells were washed with PBS to remove detached and suspended cells. The remaining cells were given new medium, ZrO2, PLTm vesicles, or PLT@ZrO2, respectively. The concentration of $\mathrm{ZrO} 2 \mathrm{NPs}$ used in this study was $50 \mu \mathrm{g} / \mathrm{mL}$. After $24 \mathrm{~h}$, pictures of the scratches were taken under an inverted phase contrast microscope (Axio Observer, ZEISS, Germany), and the extent of wound healing recovery was assessed by the wound area in each group.

\section{Migration and Invasion Assays}

Transwell Permeable Supports (Corning Inc., USA) were used to assay cell migration and invasion. Hela cells (about $1 \times$ $10^{4}$ /well) suspended in $200 \mu \mathrm{l}$ serum-free medium with $\mathrm{ZrO} 2$, PLTm vesicles, or PLT@ZrO2, were plated onto Transwell filter inserts in 24-well plates for migration assays. The concentration of $\mathrm{ZrO} 2 \mathrm{NPs}$ used in this study was $50 \mu \mathrm{g} / \mathrm{mL}$. The corresponding cell suspensions plated onto Transwell filter inserts coated with Matrigel were used for invasion assays. We used $500 \mu \mathrm{l}$ DMEM containing $10 \%$ FBS plated in the lower chambers as a chemoattractant. After incubation for $24 \mathrm{~h}$, a cotton swab was used to remove the cells in the upper chamber. Cells on the bottom side were stained with Calcein-AM (Jang et al., 2012) 
and photographed under an inverted fluorescence microscope at excitation wavelength of $530 \mathrm{~nm}$ and emission wavelength of $590 \mathrm{~nm}$. Pictures were quantified and analyzed using MetaXpress software (Molecular Devices).

\section{Biocompatibility of PLT@ZrO2}

Hemolytic rates and RAW 264.7 macrophages phagocytosis were conducted to estimate the biocompatibility of PLT@ZrO2. After incubating ZrO2 NPs or PLT@ZrO2 (from 0.1 to 0.8 $\mathrm{mg} / \mathrm{mL}$ ) with $5 \%$ red blood cell suspension at $37^{\circ} \mathrm{C}$ for $2 \mathrm{~h}$, the mixture was centrifuged (3,500 rpm, $5 \mathrm{~min}$ ), and the absorbance at $545 \mathrm{~nm}$ of the supernatant was measured by a microplate reader. Ultra-pure water and PBS incubated with 5\% red blood cell suspension was used as a positive and negative control, respectively. We calculated the hemolytic ratio as follows: hemolytic rate $\%=$ (experimental sample absorbancenegative control absorbance)/(positive control absorbancenegative control absorbance) $\times 100 \%$. RAW 264.7 macrophages $\left(1 \times 10^{5} /\right.$ well $)$ were seeded into a 6 -well plate and treated with $2 \mathrm{~mL}$ PLT@ZrO2-RhB or ZrO2-RhB for $24 \mathrm{~h}$ to assess the ability of PLT@ZrO2 to evade the immune response. In the nanocomposite, the concentration of $\mathrm{ZrO} 2 \mathrm{NPs}$ was $50 \mu \mathrm{g} / \mathrm{mL}$. After staining the cell nuclei with Hoechst 33342 (Crowley et al., 2016), pictures taken from a laser confocal fluorescence microscope (LCFM) (TCS SP8 CARS, Leica, Germany) were used to assess the phagocytosis of PLT@ZrO2 by macrophages and the fluorescence intensity.

\section{PLT@ZrO2 Distribution Assay In vivo}

Hela tumor-bearing mice were injected through the tail vein with the Cy5-labeled PLT@ZrO2 or Cy5-labeled ZrO2 to evaluate the targeting capability of PLT@ZrO2 in vivo. The dosage of Cy5 in the nanocomposite was $3 \mu \mathrm{g} / \mathrm{kg}$. After administration, a Xenogen IVIS Lumina XR imaging system (Caliper Life Sciences, USA) was applied to detect the fluorescence intensity of the mice at 6,24 , and $48 \mathrm{~h}$, respectively. The mice were then euthanized, and tumor tissues and visceral tissues were harvested for further imaging. Then the tumor tissues were made into frozen sections and observed under an inverted fluorescence microscope.

\section{PLT@ZrO2 Treatment in Cervical Cancer-Bearing Mice}

To explore in vivo anticancer effect, we injected Hela cells $\left(1 \times 10^{6}\right)$ in $100 \mu \mathrm{L}$ PBS through the hypodermic and tail vein, to establish subcutaneous tumors and metastasis tumors, respectively. Tumor volume was calculated as follow: $\mathrm{V}=1 / 2 \times$
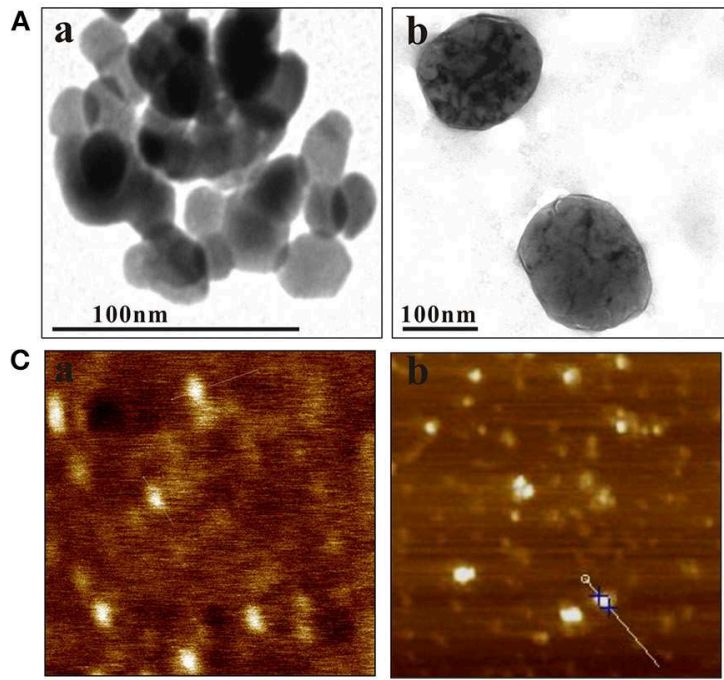

D

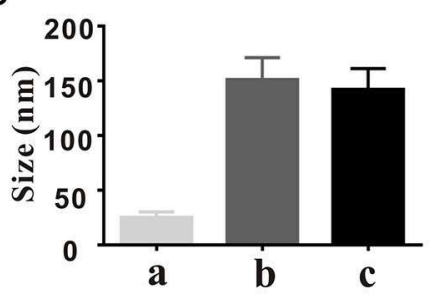

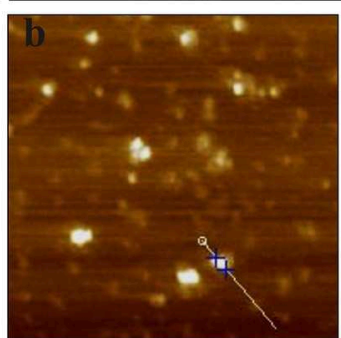

E

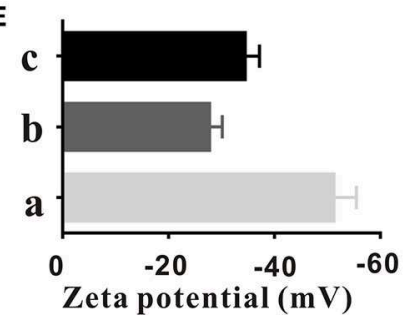

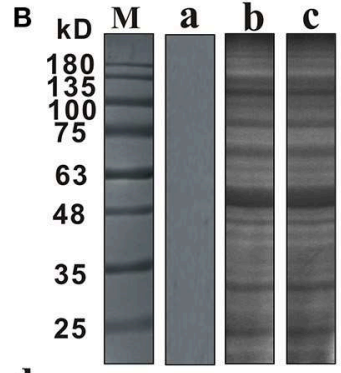

d

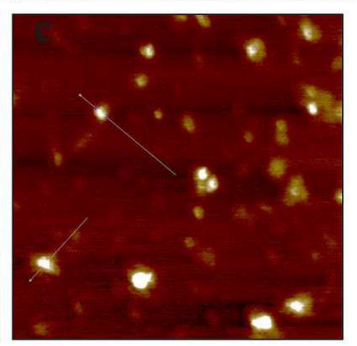

$\mathbf{F}$

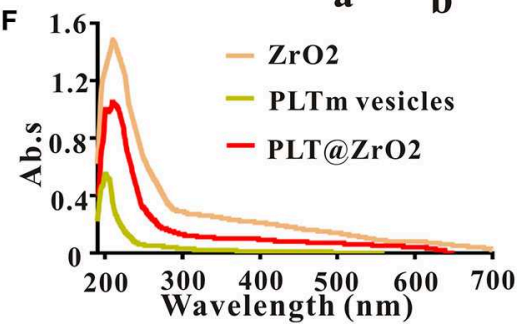

FIGURE 1 | Characterization of PLT@ZrO2. (A) TEM images of ZrO2, PLTm vesicles, and PLT@ZrO2. Scale bar: 100 nm. a, ZrO2; b, PLTm vesicles; c, PLT@ZrO2. (B) SDS-PAGE protein assessment. M, Marker; a, ZrO2; b, PLTm vesicles; c, PLT@ZrO2. (C) The heights of ZrO2, PLTm vesicles, and PLT@ZrO2 observed under AFM. a, ZrO2; b, PLTm vesicles; c, PLT@ZrO2; d, Quantitative assay of heights of ZrO2, PLTm vesicles, and PLT@ZrO2. (D) The particle size of ZrO2, PLTm vesicles, and PLT@ZrO2. a, ZrO2; b, PLTm vesicles; c, PLT@ZrO2. (E) Zeta potential of ZrO2, PLTm vesicles, and PLT@ZrO2. a, ZrO2; b, PLTm vesicles; c, PLT@ZrO2. (F) UV-Vis spectra of ZrO2, PLTm vesicles, and PLT@ZrO2. 
$\mathrm{D} \times \mathrm{L}^{2}$, where $\mathrm{V}$ refers to volume, $\mathrm{D}$ refers to the longitudinal diameter and L refers to the latitudinal diameter. Day 0 (D0) represents the first day when subcutaneous tumor volumes exceed $100 \mathrm{~mm}^{3}$. Fifteen mice were randomly assigned to 3 groups $(n=5)$ and injected with $100 \mu \mathrm{L}$ of PBS, PLTm, or PLT@ZrO2 through tail vein once a day for 3 consecutive days. The dosage of $\mathrm{ZrO} 2$ was $50 \mathrm{mg} / \mathrm{kg} / \mathrm{d}$. The tumor sizes and body weights of the mice were measured, and tumor volumes were calculated once every 4 days. All mice were euthanized on day 14 (D14). Whole blood, tumors, and internal organs (hearts, livers, spleens, lung, and kidney) were collected. Whole blood was collected and measured by a five-part differential hematology analyzer (BC-5390, Mindray, China). After centrifugation (3,000 rpm, $10 \mathrm{~min})$, an automatic biochemical analyzer (7100, HITACHI, Japan) and an immunology analyzer (Cobas 6000 e601, ROCHE, USA) were applied to detect the serum enzyme levels. All collected organs and tumors were fixed in $4 \%$ paraformaldehyde and frozen at $-80^{\circ} \mathrm{C}$. The frozen tumor tissues were used for Western blotting analysis. The fixed tissues were embedded in paraffin, sliced into sections, and then stained for $\mathrm{HE}$ and immunofluorescence.

\section{Immunofluorescence Analysis}

Immunofluorescence analysis was performed by immunofluorescence staining of TUNEL, N-cadherin, Vimentin, E-cadherin, $\beta$-catenin, and Fibronectin according to standard protocols (Hseu et al., 2019). The sections were then counterstained with DAPI (Chazotte, 2011), observed under an inverted fluorescence microscope, and photographed.

\section{Western Blotting Analysis}

Proteins were extracted from tumor tissue lysates using RIPA buffer. The concentrations of total proteins were quantified with a BCA protein assay kit. Protein expressions were assessed by
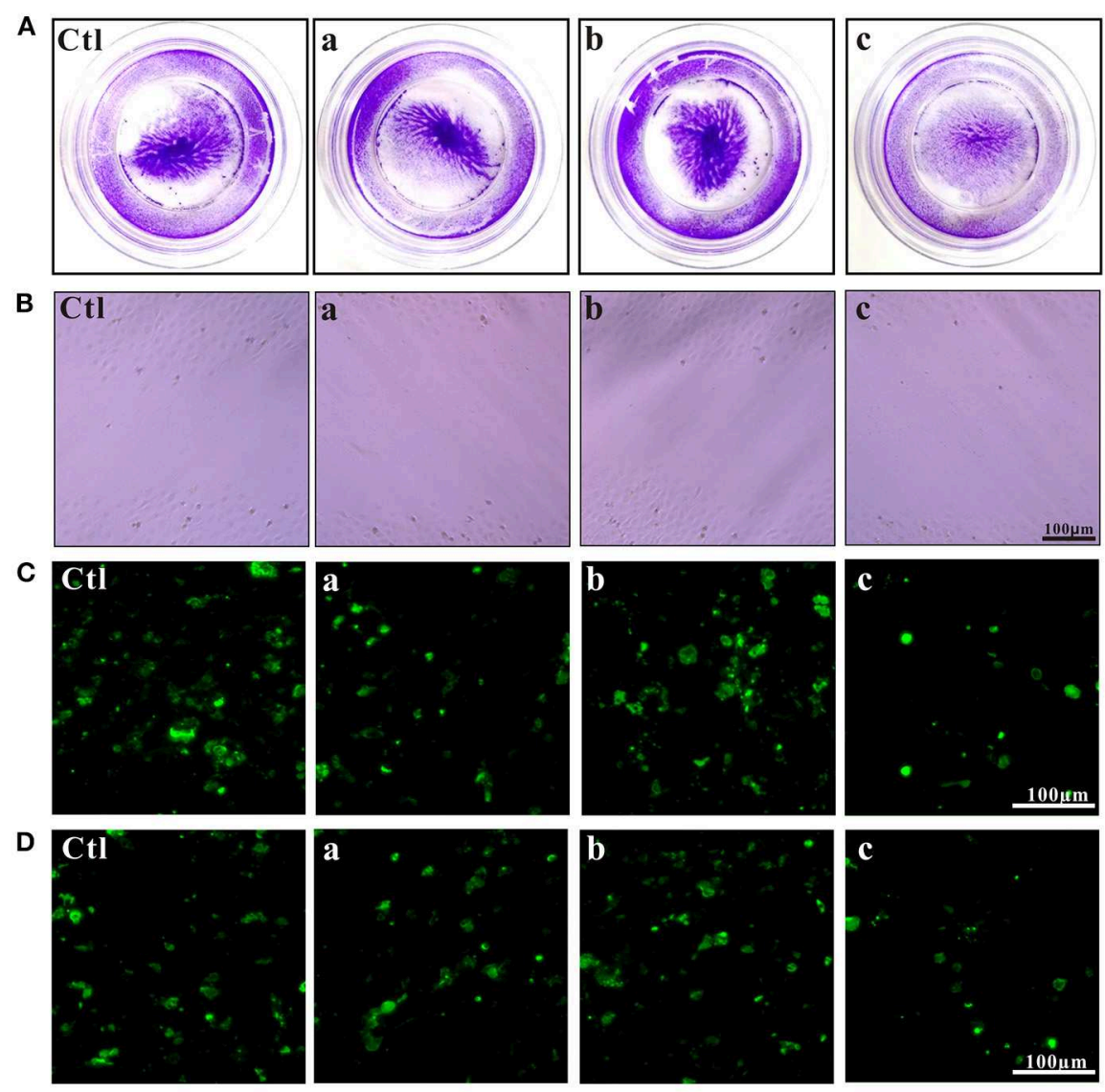
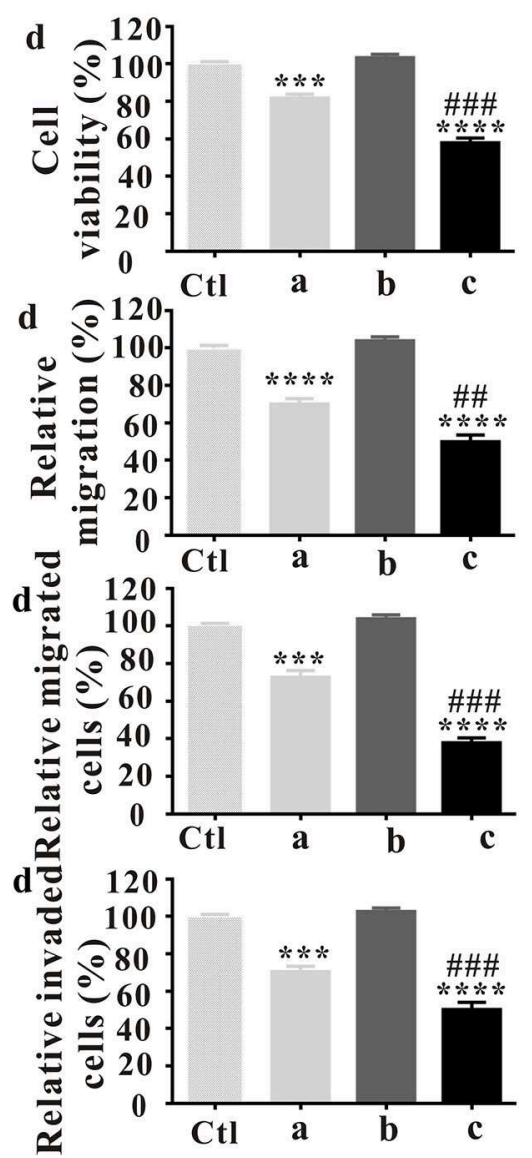

FIGURE 2 | In vitro antitumor effects of PLT@ZrO2. (A) Cell viability assay after treated with ZrO2, PLTm vesicles, or PLT@ZrO2. Ctl, control; a, ZrO2; b, PLTm vesicles; c, PLT@ZrO2; d, Semi-quantitative assay of cell viability after treated with ZrO2, PLTm vesicles, or PLT@ZrO2. (B) Scratch-wound healing recovery assays after treated with ZrO2, PLTm vesicles, or PLT@ZrO2, respectively. Ctl, control; a, ZrO2; b, PLTm vesicles; c, PLT@ZrO2; d, Semi-quantitative assay of migration rate after treated with ZrO2, PLTm vesicles, or PLT@ZrO2. (C) Transwell migration assay after treated with ZrO2, PLTm vesicles, or PLT@ZrO2, respectively. Ctl, control; a, ZrO2; b, PLTm vesicles; c, PLT@ZrO2; d, Semi-quantitative assay of migration rate after treated with ZrO2, PLTm vesicles, or PLT@ZrO2. (D) Transwell invasion assays after treated with ZrO2, PLTm vesicles, or PLT@ZrO2, respectively. Ctl, control; a, ZrO2; b, PLTm vesicles; c, PLT@ZrO2; d, Semi-quantitative assay of invasion rate after treated with ZrO2, PLTm vesicles, or PLT@ZrO2. Data are mean $\pm \mathrm{SD}(n=3)$. Compared to the control group: ${ }^{\star \star \star} p<0.001$ and ${ }^{\star \star \star \star} p<0.0001$; compared to the ZrO2 group: \#\#p 0.01 and $\# \# \# p<0.001$. 
immunoblot analysis of tumor tissue lysates $(40 \mu \mathrm{g})$ in the presence of rabbit antibodies against Snail, Smad4, Vimentin, Slug, N-cadherin, MMP2, Smad2, GAPDH (1:1,000, Servicebio Technology, China), and mouse antibodies against E-cadherin and $\beta$-actin (1:1,000, Servicebio Technology, China), according to standard protocols (Hseu et al., 2019).

\section{Statistical Analysis}

SPSS Software 20.0 was used for statistical analysis. Data are expressed as the mean $\pm \mathrm{SD}$. One-way ANOVA was used to assess the differences between groups, and Tukey's posttest was performed ( $*$ indicates $p<0.05,{ }^{* *}$ indicates $p<0.01$, *** indicates $p<0.001$, and ${ }^{* * * *}$ indicates $p<0.0001$ ).

\section{RESULTS AND DISCUSSION \\ Characterization of the PLT@ZrO2 Nanocomposite}

$\mathrm{ZrO} 2 \mathrm{NPs}$ were monodispersed with diameters averaging $25 \mathrm{~nm}$ (Figure 1Aa), larger than the spherical shaped $\mathrm{ZrO} 2 \mathrm{NPs}$ (of 9-11 nm) extracted from E. globulus leaf (Balaji et al., 2017). The diameter of PLTm vesicles was about $150 \mathrm{~nm}$ (Figure 1Ab), consistent with the previous report (Shang et al., 2019). Ultrasonic treatment facilitated encapsulation of $\mathrm{ZrO} 2 \mathrm{NPs}$ by
PLTm vesicles to form PLT@ZrO2 nanocomposites. As shown in Figure 1Ac, several $\mathrm{ZrO} 2$ NPs were camouflaged by one PLTm vesicle. The SDS-PAGE results (Figure 1B) indicated that the proteins of PLT@ZrO2 nanocomposites were almost the same as PLTm nanovesicles. The heights of ZrO2 NPs, PLTm nanovesicles and PLT@ZrO2 nanocomposites observed under an AFM were $30.0 \pm 7.2,150 \pm 21.1$, and $142 \pm 20.2 \mathrm{~nm}$ (Figure 1C). Dynamic light scattering (DLS) data (Figure 1D) showed that the average size of PLT@ZrO2 nanocomposites were $140 \mathrm{~nm}$, slightly smaller than PLTm nanovesicles and consistent with the data from AFM. Zeta potential of ZrO2 NPs was -51.5 $\pm 3.1 \mathrm{mV}$. After encapsulation, Zeta potential of PLT@ZrO2 was $-34.5 \pm 2.7 \mathrm{mV}$, similar to that of PLTm nanovesicles $(-27.8$ $\pm 2.4 \mathrm{mV}$ ) (Figure 1E), indicating successful camouflage. Results from UV-vis spectrometry (Figure 1F) showed that PLT@ZrO2 possesses absorption peaks at 210 and $200 \mathrm{~nm}$, consistent with those of $\mathrm{ZrO} 2$ NPs and PLTm nanovesicles detected alone. These findings demonstrated the successful preparation of PLT@ZrO2.

\section{In vitro Antitumor Effects of PLT@ ZrO2 In vitro Effects of PLT@ZrO2 Nanocomposite on Hela Cells Viability}

Before investigating the anti-metastatic potential of PLT@ZrO2, we used crystal violet staining to assess the viability of Hela cells
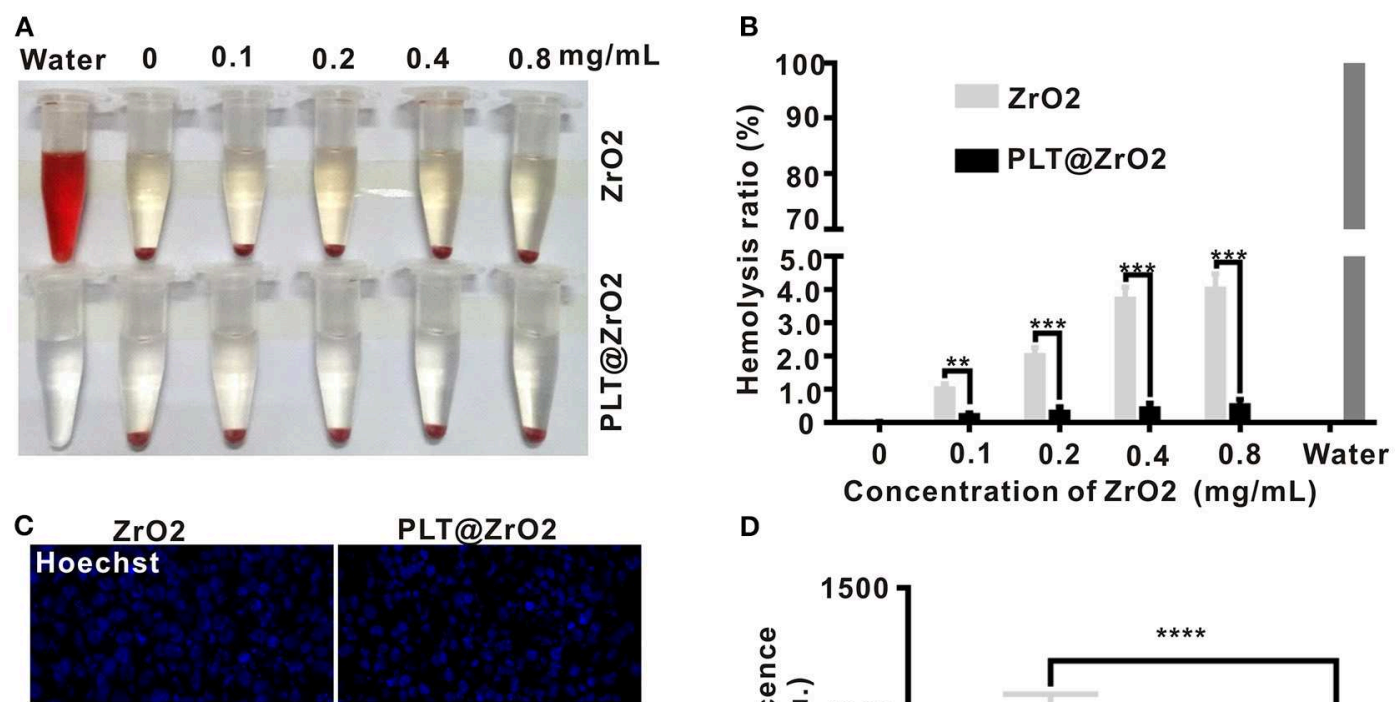

D
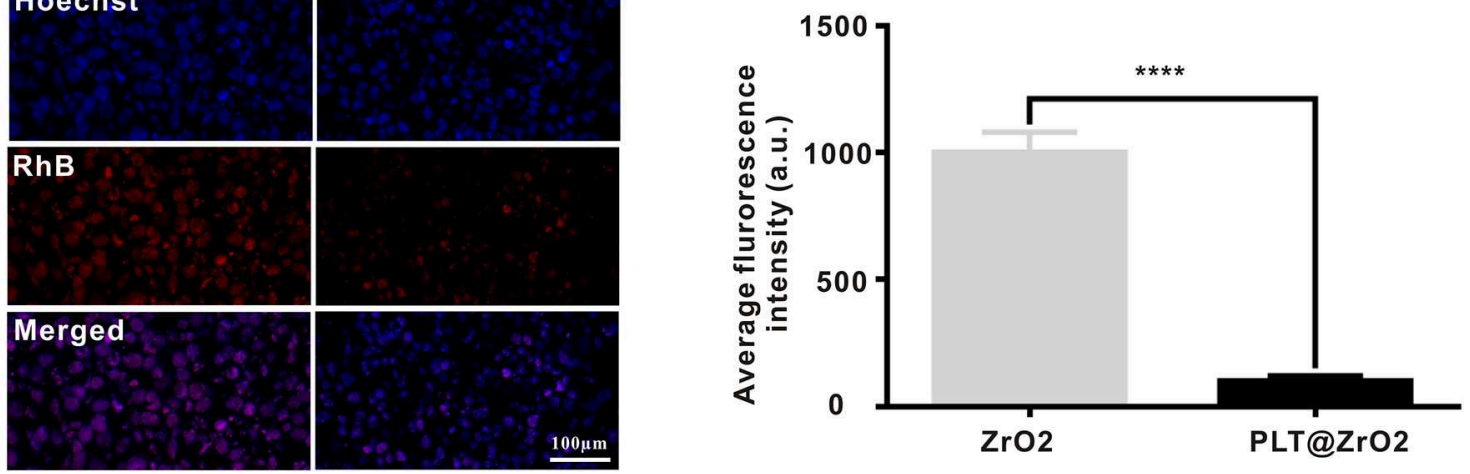

FIGURE 3 | Biocompatibility of PLT@ZrO2. (A) Pictures of RBC suspensions after treatment with various concentrations of ZrO2 or PLT@ZrO2. (B) Hemolytic rate after treatment with various concentrations of ZrO2 or PLT@ZrO2. (C) Images of RAW264.7 cells upon culture with ZrO2-RhB or PLT@ZrO2-RhB for 24h taken by a LCFM. Scale bar: $100 \mu \mathrm{m}$. (D) Average fluorescence intensity of RAW264.7 cells after cultured with ZrO2-RhB or PLT@ZrO2-RhB for 24 h. Data are presented as mean $\pm \mathrm{SD}(n=3)$. Compared to the ZrO2 group: ${ }^{* *} p<0.01,{ }^{* \star *} p<0.001$, and ${ }^{* * *} p<0.0001$. 
after treatment with ZrO2, PLTm vesicles and PLT@ZrO2. Our results showed that compared with ZrO2, PLT@ZrO2 greatly inhibited viability, indicating that PLT camouflaging enhanced the inhibitory effect of $\mathrm{ZrO} 2 \mathrm{NPs}$ (Figure 2A). This may be due to increased local concentration of $\mathrm{ZrO} 2$ when PLTm vesicles bind to tumor cells (Shang et al., 2019).

\section{PLT@ZrO2 Potently Inhibits Hela Cells Migration and Invasion}

In the scratch-wound healing recovery assay (Figure 2B), $\mathrm{ZrO} 2$ NPs partly inhibited wound healing of Hela cells. PLT@ZrO2 greatly inhibited Hela cell migration, while PLTm did not inhibit Hela cells migration.

As shown in Figure 2C, treatment with $\mathrm{ZrO} 2$ NPs alone inhibited the migration of Hela cells by $\sim 30 \%$, and PLT@ZrO2 exerted significant additional anti-migration effect. The Transwell invasion assay (Figure 2D) revealed that PLT@ZrO2 dramatically inhibited cells invading through Matrigel-coated filters, thus significantly decreasing the metastasis of Hela cells. The above results demonstrated that PLTm vesicle camouflaging improved the inhibitory effect of $\mathrm{ZrO} 2$ NPs on the migration and invasion of Hela cells.

\section{Biocompatibility of the PLT@ZrO2 Nanocomposite}

We evaluated the toxicities of $\mathrm{ZrO} 2$ NPs and PLT@ZrO2 by observing their hemolytic effects on RBCs. As shown in Figure 3A, the hemolytic rate after treatment with $\mathrm{ZrO} 2$ NPs, even in the concentration of $0.8 \mathrm{mg} / \mathrm{mL}$, was $<4.5 \%$. PLT@ZrO2 had a value $(0.5 \pm 0.29 \%)$ significantly lower than that of $\mathrm{ZrO} 2 \mathrm{NPs}$ (Figure 3B), indicating that PLTm vesicle camouflaging improved the biosafety and hemocompatibility of $\mathrm{ZrO} 2$ NPs.

ZrO2 NPs and PLT@ZrO2 labeled with RhB (red fluorescent signals) were applied to detect the anti-phagocytosis effect. After incubation with $\mathrm{ZrO} 2-\mathrm{RhB}$ for 24h, RAW264.7 macrophages showed strong red fluorescent signals (Figure 3C), demonstrating phagocytosis. However, weak fluorescent signals were observed after treatment with PLT@ZrO2-RhB, indicating that phagocytic activity was significantly weakened. Macrophages treated with PLT@ZrO2-RhB showed lower average fluorescence than that of cells treated with $\mathrm{ZrO} 2-\mathrm{RhB}$ (Figure 3D). The above results suggested that PLTm nanovesicle camouflaging prevents phagocytosis of $\mathrm{ZrO} 2 \mathrm{NPs}$ by macrophages, thus reducing their clearance and extending the circulation time.
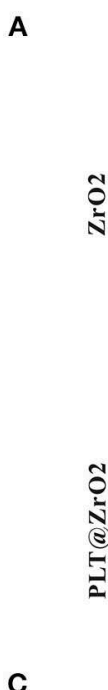

C
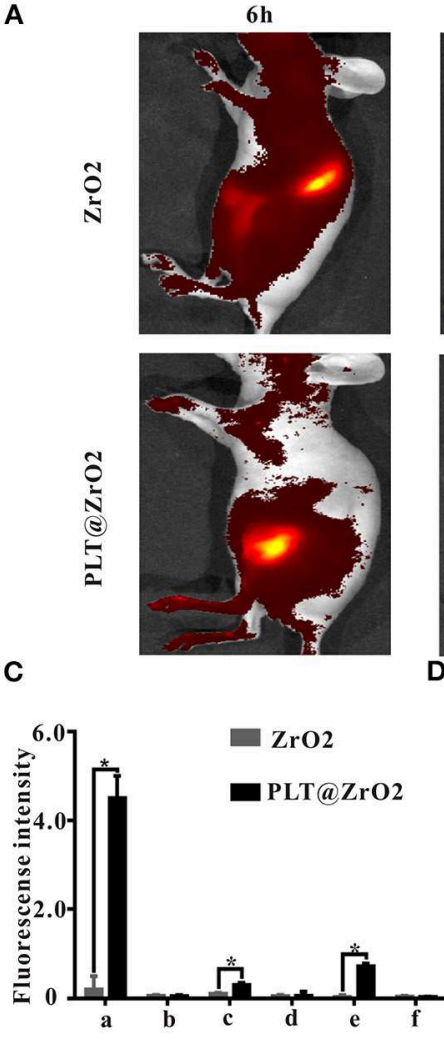

$24 h$

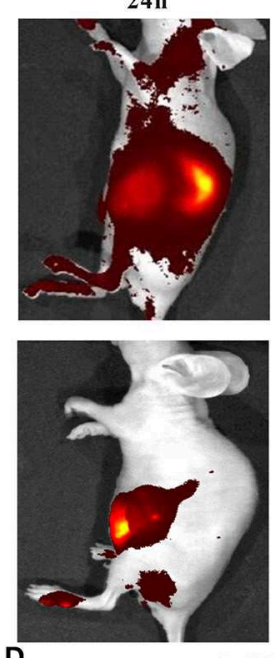

$48 \mathrm{~h}$

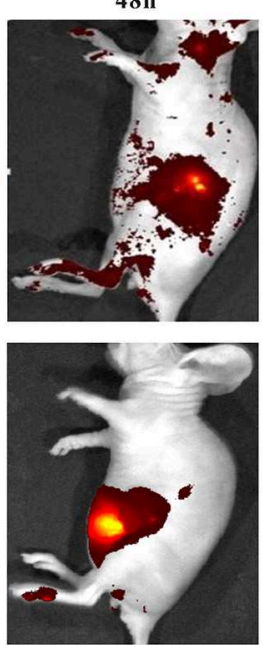

B ZrO2 PLT@ $\mathrm{ZrO2}$

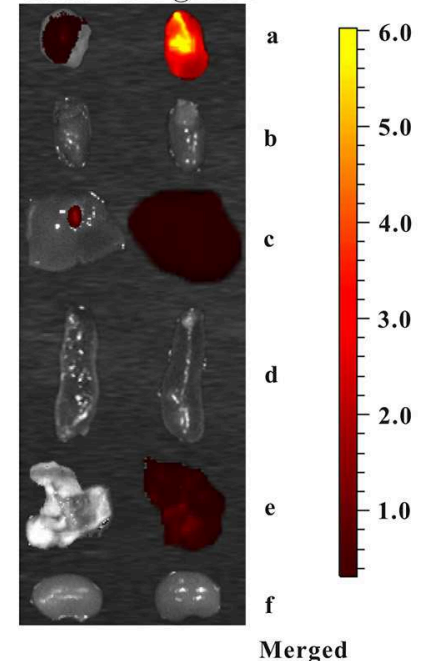

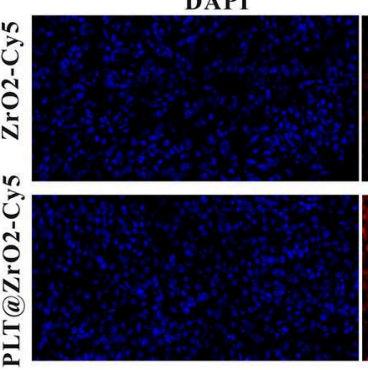
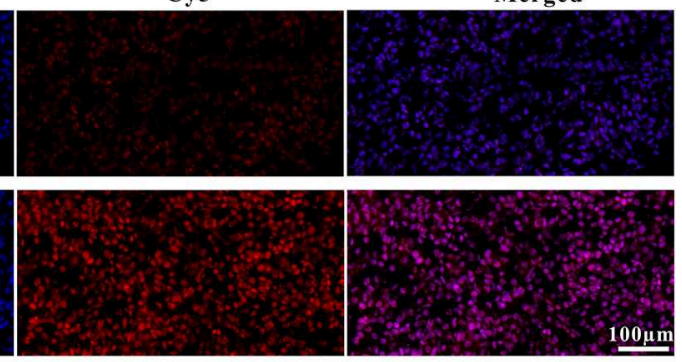

$100 \mu \mathrm{m}$

FIGURE 4 | In vivo distribution of PLT@ZrO2 through intravenous injection. (A) In vivo fluorescent images of nude mice at 6, 24, and 48h upon intravenous treatment with ZrO2-Cy5 or PLT@ZrO2-Cy5. (B) Bioluminescent images of tumors and visceral tissues at 48h post-treatment with ZrO2-Cy5 or PLT@ZrO2-Cy5. (C) Semi-quantitative assay of fluorescent intensities of tumor and other tissue samples. a, Tumor; b, heart; c, liver; d, spleen; e, lung; f, kidney. (D) Fluorescent images of tumors from nude mice $48 \mathrm{~h}$ upon administration of ZrO2-Cy5 or PLT@ZrO2-Cy5. Scale bar: $100 \mu \mathrm{m}$. Data are presented as the mean \pm SD ( $n=3$ ). Compared to the ZrO2 group: * $p<0.05$. 


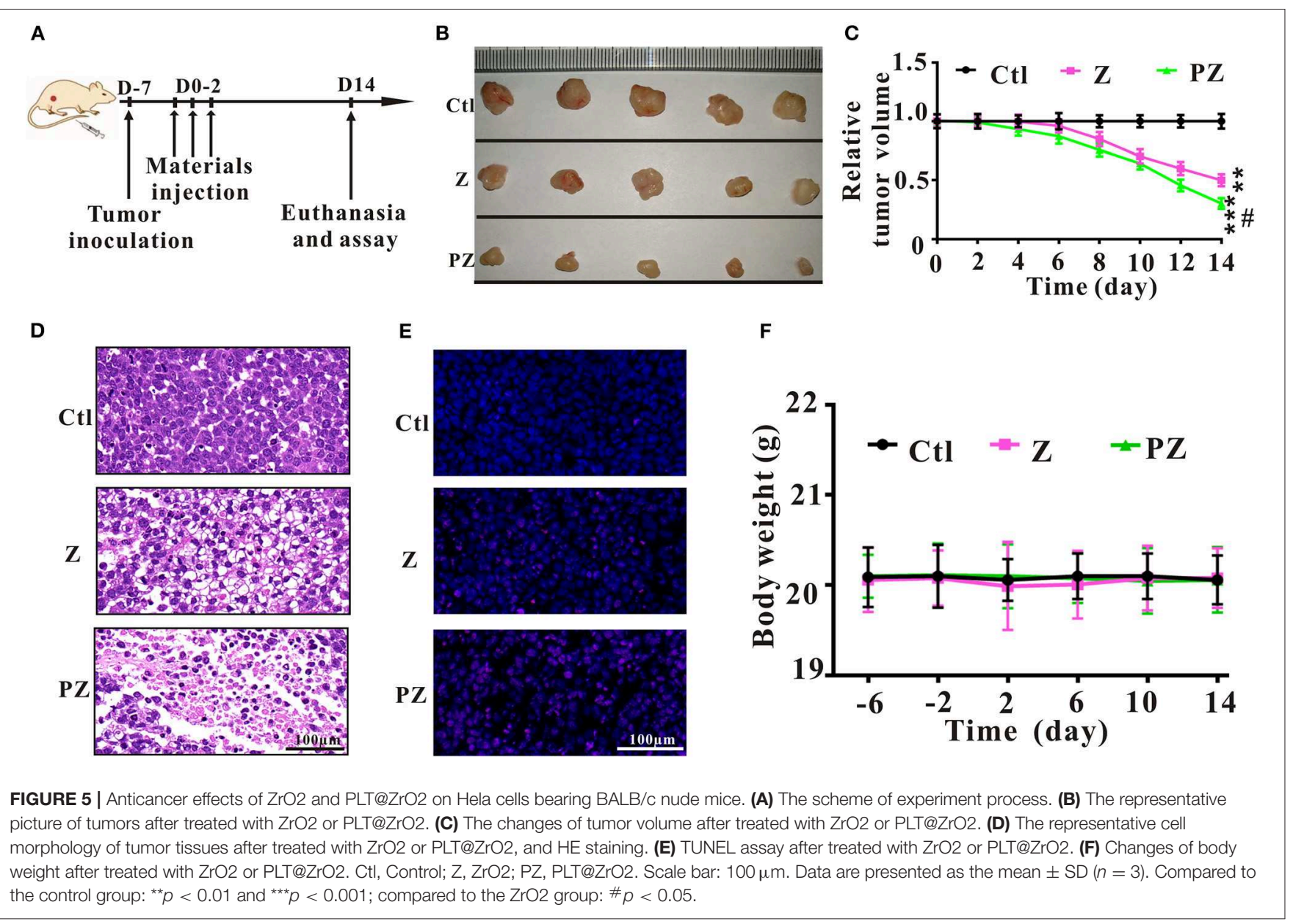

The above results suggested that PLT@ZrO2 nanocomposite outperformed $\mathrm{ZrO} 2$ NPs in biocompatibility.

\section{In vivo Distribution of PLT@ZrO2 Through Intravenous Injection}

Due to the ability of PLTm vesicles to escape phagocytosis by immune cells and bind to tumor cells (Shang et al., 2019), PLT@ZrO2 has the potential to accumulate in tumors that have metastasized. To verify this hypothesis, we assessed biodistribution of PLT@ZrO2 using PLT@ZrO2 conjugated by Cy5. We used $\mathrm{ZrO} 2$ NPs conjugated by $\mathrm{Cy} 5$ as a control. As shown in Figure 4A, after administration of PLT@ZrO2Cy5, we observed increased fluorescent intensity at tumor sites compared to $\mathrm{ZrO} 2-\mathrm{Cy} 5$, demonstrating increased retention of PLT@ZrO2. At $48 \mathrm{~h}$ after intravenous injection, PLT@ZrO2Cy5 retentions in tumor, liver and lungs were greater than those of $\mathrm{ZrO} 2-\mathrm{Cy} 5(P<0.05)$ (Figures 4B,C), and more intense red fluorescence in tumor tissue in the PLT@ZrO2 group was observed (Figure 4D), suggesting that retention of PLT@ZrO2-Cy5 in tumor sites exceeded that of $\mathrm{ZrO} 2$ Cy5 and PLT@ZrO2 nanocomposites have excellent tumor targeting efficiency.

\section{Antitumor Effects of PLT@ZrO2 In vivo}

To further explore the anticancer effect of PLT@ZrO2, we conducted in vivo assays in tumor-bearing mice that underwent Hela cells injection (Figure 5A). Compared to the $\mathrm{ZrO} 2$ group, tumor volumes in the PLT@ZrO2 group were smaller (Figures 5B,C), indicating that PLT@ZrO2 significantly inhibited tumor growth. As shown by $\mathrm{HE}$ (Figure 5D) and TUNEL staining (Figure 5E), we observed more necrotic and apoptotic cells in tumor tissues with PLT@ZrO2 compared to $\mathrm{ZrO} 2$. The above findings demonstrate that PLT@ZrO2 induced stronger anticancer effects than $\mathrm{ZrO} 2$ alone. The body weights of mice in PLT@ZrO2 group did not decline, indicating no obvious systemic toxicity (Figure $5 \mathrm{~F}$ ).

Tumor metastasis, an important feature of malignant tumors, is a complex and multistep process, regulated by genetic, and epigenetic changes (Gupta and Massagué, 2006; Tiwari et al., 2013). It is recognized that epithelial-mesenchymal transition (EMT) plays an important role in invasion and metastasis (van Zijl et al., 2009). EMT initiates the early steps of tumor metastasis and spread of tumor cells by endowing them greater motility and invasiveness (Thiery et al., 2009).

$\mathrm{Wnt} / \beta$-catenin signaling plays a vital role in accelerating the process of EMT and metastasis (Zhou et al., 2016; Liu et al., 2017). 


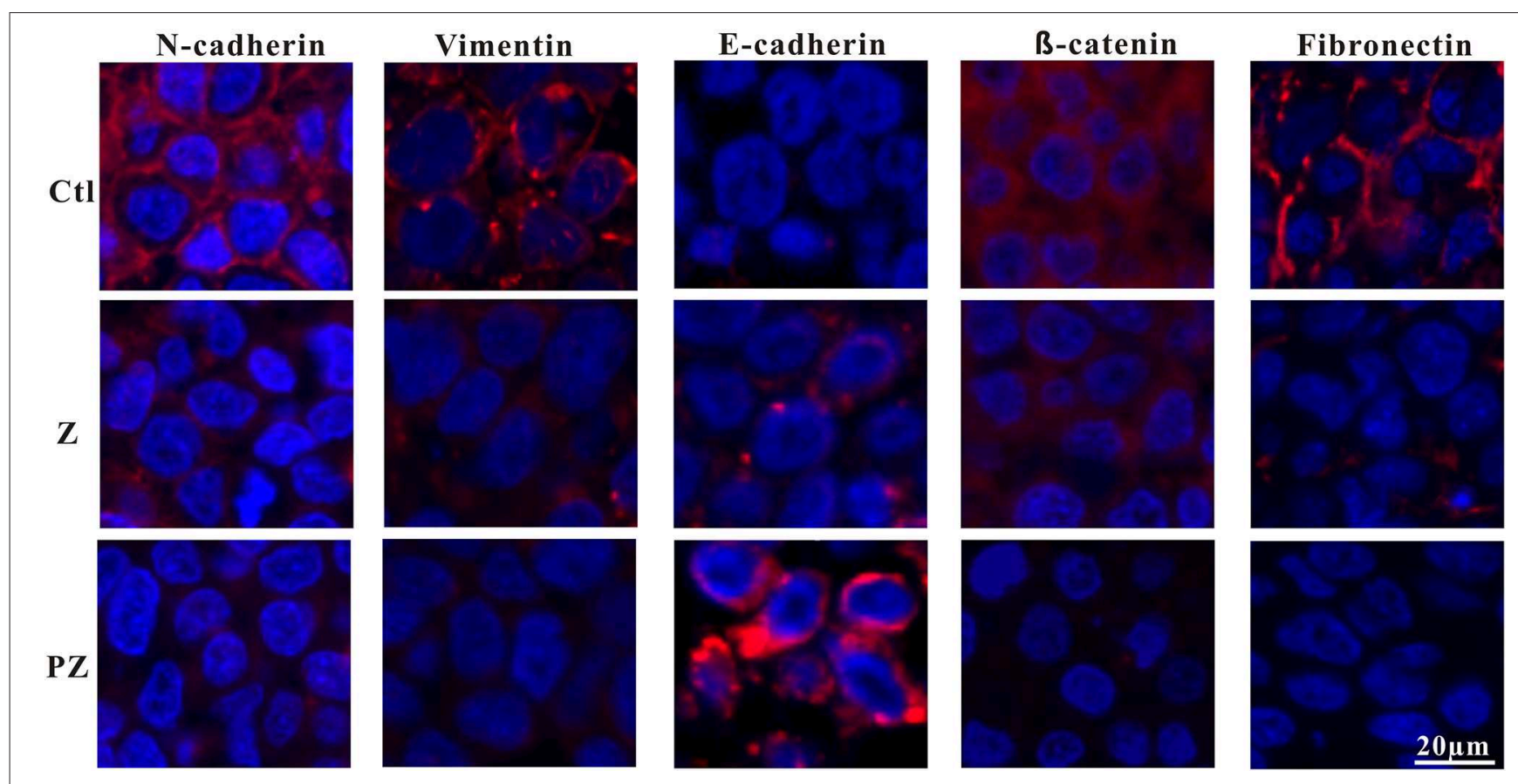

FIGURE 6 | Immunofluorescence pictures of tumor sections after treated with ZrO2 or PLT@ZrO2 and stained with N-cadherin, Vimentin, E-cadherin, $\beta$-catenin, and Fibronectin. Ctl, Control; Z, ZrO2; PZ, PLT@ZrO2. Scale bar: $20 \mu \mathrm{m}$.

Constitutive activation of the $\mathrm{Wnt} / \beta$-catenin pathway results in the reduction of E-cadherin and induction of EMT (Goto et al., 2017), thereby enabling metastasis and invasion by reducing cellto-cell contact (Onder et al., 2008). Moreover, downregulation of E-cadherin followed by EMT plays an important role in metastasis initiation (Shu et al., 2019). Previous studies have demonstrated that upregulation of $\mathrm{N}$-cadherin is associated with tumor invasion and metastasis (Watson-Hurst and Becker, 2006; Hao et al., 2012; Mrozik et al., 2018). As shown in Figure 6, compared to $\mathrm{ZrO} 2 \mathrm{NPs}$ alone, treatment with PLT@ZrO2 downregulated $\mathrm{N}$-cadherin and $\beta$-catenin (red fluorescence), and upregulated E-cadherin (red fluorescence), indicating that PLT@ZrO2 potentially inhibits tumor invasion and metastasis.

Reduction of epithelial proteins, such as E-cadherin (Onder et al., 2008), and increase of mesenchymal proteins, such as vimentin (Huber et al., 2005), are hallmarks of EMT. Vimentin, a $57 \mathrm{kDa}$ type III intermediate filament protein, is critical for cell adhesion, migration, and signaling (Ivaska et al., 2007), and is essential to the progression and prognosis of cancer through EMT (Gugnoni et al., 2016; Sun and Fang, 2016). Fibronectin, a tumor-associated extracellular matrix protein, facilitates polymerization of fibrillar components on adherent and suspended tumor cell surfaces and maintains structure and motility in cell migration (Cheng et al., 1998; Huang et al., 2008; Shi et al., 2010; Knowles et al., 2015). As shown in Figure 6, compared with ZrO2 NPs, treatment with PLT@ZrO2, reduced Fibronectin and Vimentin (red fluorescence), indicating that PLT@ZrO2 could significantly inhibit tumor invasion and metastasis.
The EMT program is regulated by 3 EMT-inducing transcription factors families: Snail, Twist and Zeb (Ansieau et al., 2014; Puisieux et al., 2014). Slug (termed Snail2), can inhibit E-cadherin expression and promote EMT (Wang et al., 2009). Previous study has demonstrated that Slug regulates malignant transformation and metastasis of various cancers (Alves et al., 2009). WNT, TGF- $\beta$, NOTCH, and SHH signaling pathways play crucial roles in activation of EMT-related transcription factors, including Snail, Slug, Zeb1/2, and Twist (Nieszporek et al., 2019).

The adhesion molecule, $\mathrm{N}$-cadherin, is related to invasive ability in cancers, and its overexpression facilitates motility and invasion (Nakajima et al., 2004). Slug and Snail inhibit Ecadherin expression; thus their overexpression promotes EMT (Hotz et al., 2007; Grzegrzolka et al., 2015). As shown in Figure 7, compared with ZrO2 NPs, treatment with PLT@ZrO2 downregulated N-cadherin, Slug, and Snail and upregulated Ecadherin, indicating that PLT@ZrO2 strongly inhibited EMT.

Matrix metallopeptidases (MMPs) degrade the extracellular matrix and basement membrane (Lengyel et al., 2001), enhancing the spread of cancer cells to distant sites (Shen et al., 2017). MMP2 and MMP9 degrade collagen IV in the extracellular basement membrane (Roomi et al., 2010) and rearrange the extracellular matrix during invasion and migration of cancer cells (Nabeshima et al., 2002; Alaseem et al., 2019). Moreover, active level of MMP2 in cancer cells is related to invasion and metastasis (Celentano et al., 2020). As shown in Figure 7, compared with ZrO2 NPs, treatment with PLT@ZrO2, significantly downregulated MMP2. 


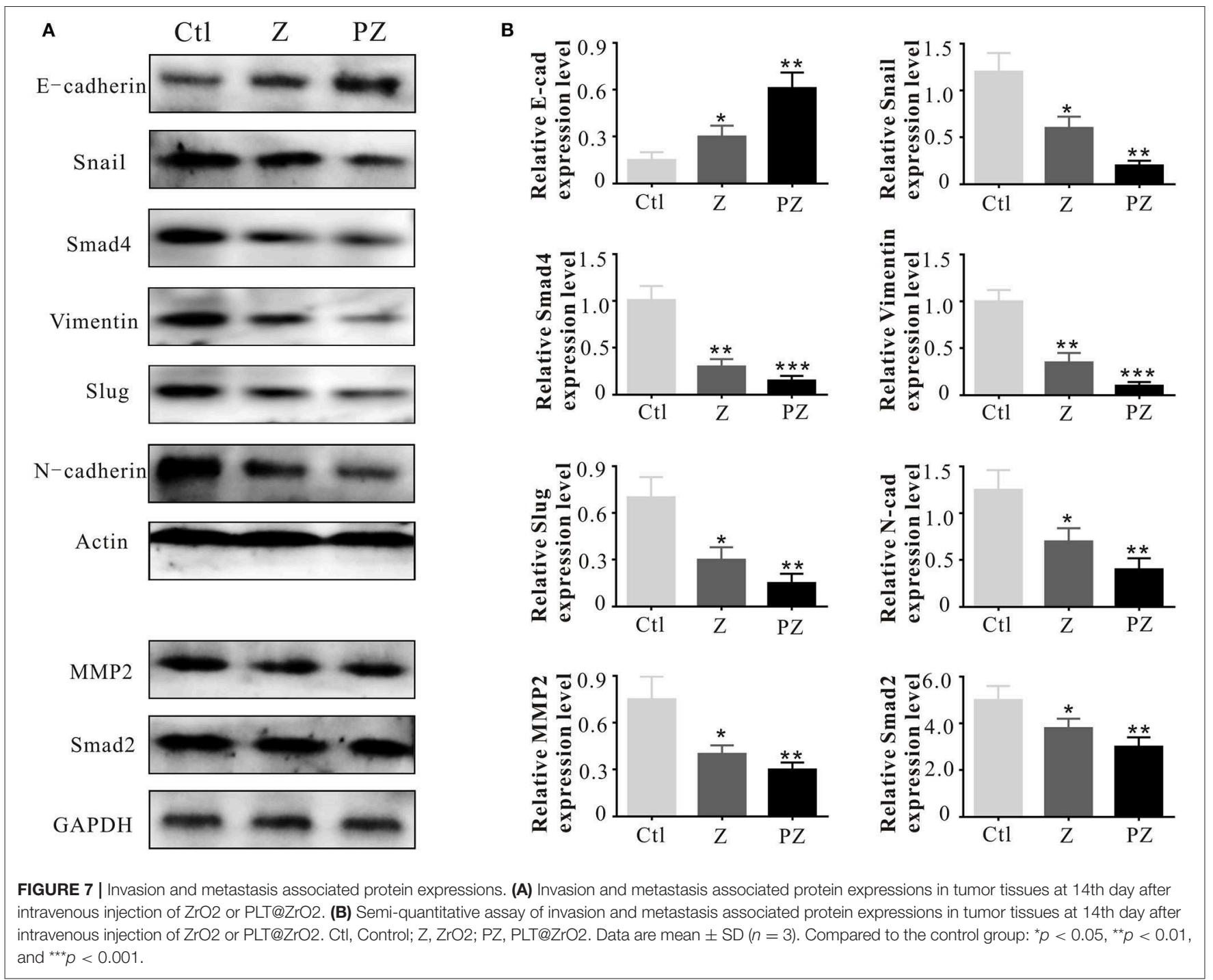

Vimentin promotes the stemness of cancer cells by phosphorylation of Slug to initiate EMT (Virtakoivu et al., 2015). Additionally, Vimentin is essential for membrane localization and appropriate activation of MT1-MMP, which is essential for endothelial sprouting (Kwak et al., 2012). As shown in Figure 7, Vimentin was down-regulated after treatment with PLT@ZrO2, indicating inhibition of EMT initiation.

The TGF- $\beta 1$ receptor, Smad, forms a heteromeric complex with Smad2 and Smad4. The activated Smad factor enters the nucleus and regulates the transcription of target genes to promote cell biological behaviors, such as proliferation, invasion, and EMT (Liu et al., 2016; Li et al., 2018). As shown in Figure 7, compared with $\mathrm{ZrO} 2 \mathrm{NPs}$, after treated with PLT@ZrO2, Smad2, and Smad4 were downregulated, indicating that PLT@ZrO2 strongly inhibited tumor proliferation, invasion, and EMT.
We observed lung and liver metastasis in the control and ZrO2 groups, while metastasis in the PLT@ZrO2 group was absent (Figure 8A). The maximum cross sections of lungs and livers stained by HE showed that the size of lungs and livers metastasis foci were larger in the control group compared to the $\mathrm{ZrO} 2$ group, while no metastasis foci were found in the sections of lungs and livers in the PLT@ZrO2 group (Figure 8B), indicating that PLT@ZrO2 could inhibit metastasis to the lungs and liver.

\section{Toxic and Side Effects of Vital Tissues and Organs}

After treatment with PLT@ZrO2, white blood cell (WBC), RBC and PLT counts did not decrease (Table 1), indicating that PLT@ZrO2 did not induce hematological toxicity. To assess the effects of PLT@ZrO2 on visceral organs, serum enzyme level detection and histological assessment were performed. 


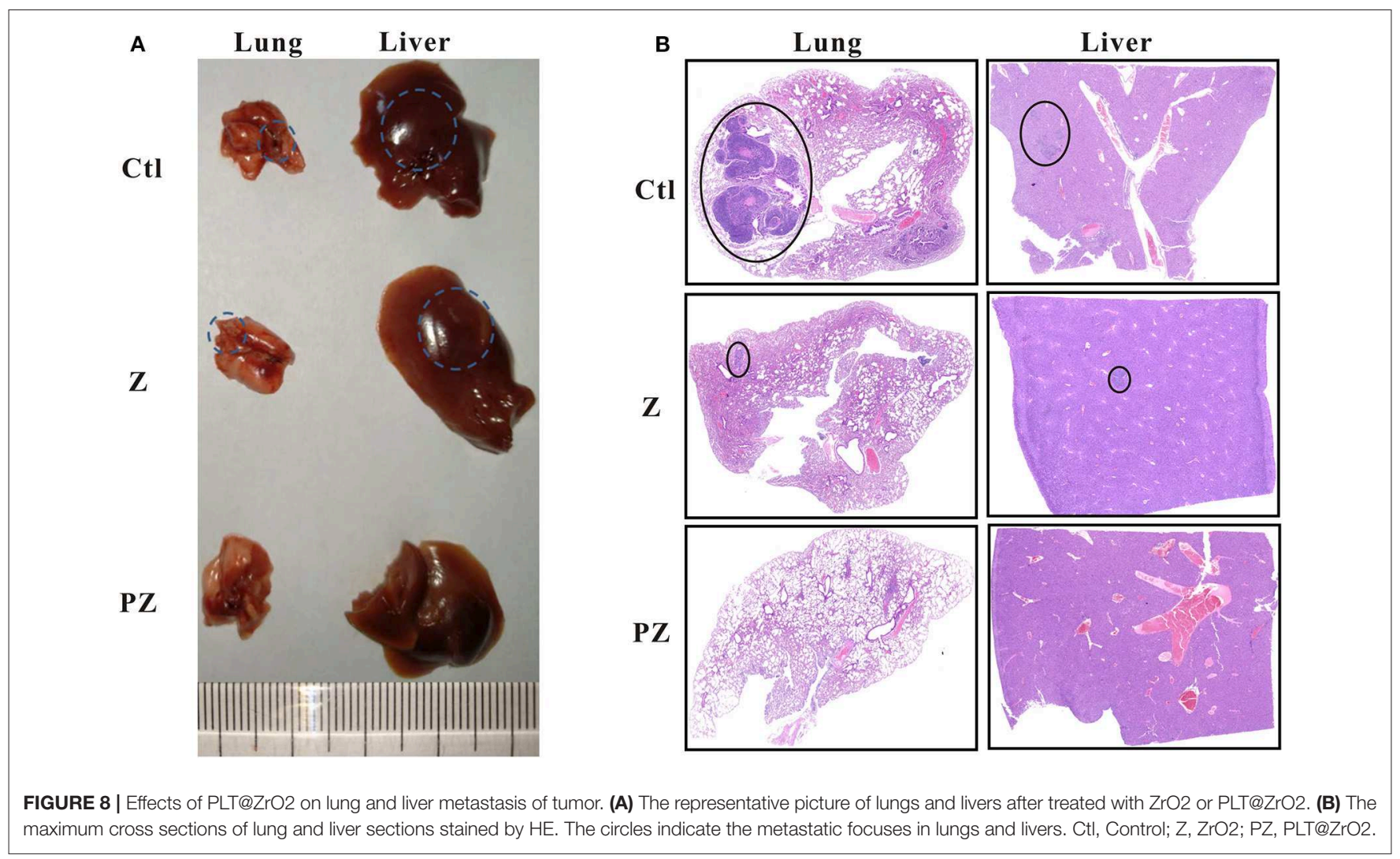

TABLE 1 | The blood cell counts, the enzyme level and myocardial enzyme spectrum analysis of tumor bearing mice after treated with ZrO2, and PLT@ZrO2.

\begin{tabular}{lccc}
\hline & Control & ZrO2 & PLT@ ZrO2 \\
\hline Blood cell count & & & \\
WBC $\left(10^{9} / \mathrm{L}\right)$ & $7.4 \pm 0.3$ & $7.3 \pm 0.5$ & $7.4 \pm 0.5$ \\
RBC $\left(10^{12} / \mathrm{L}\right)$ & $11.3 \pm 1.2$ & $11.3 \pm 1.2$ & $11.3 \pm 1.0$ \\
HGB $(\mathrm{g} / \mathrm{dL})$ & $14.6 \pm 0.5$ & $14.5 \pm 0.4$ & $14.5 \pm 0.6$ \\
HCT $(\%)$ & $49.2 \pm 1.4$ & $49.2 \pm 1.3$ & $49.0 \pm 1.5$ \\
PLT $\left(10^{11} / \mathrm{L}\right)$ & $8.6 \pm 0.4$ & $8.5 \pm 0.5$ & $8.4 \pm 0.6$ \\
Serum enzyme level & & & \\
ALT $(\mathrm{U} / \mathrm{L})$ & $25.5 \pm 2.4 \uparrow$ & $19.8 \pm 1.8 \uparrow$ & $9.5 \pm 0.6$ \\
AST $(\mathrm{U} / \mathrm{L})$ & $108.8 \pm 2.3 \uparrow$ & $97.9 \pm 2.2 \uparrow$ & $48.2 \pm 2.4$ \\
Urea $(\mathrm{mmol} / \mathrm{L})$ & $2.1 \pm 0.2$ & $2.1 \pm 0.2$ & $2.2 \pm 0.3$ \\
CRE $(\mu \mathrm{mol} / \mathrm{L})$ & $6.7 \pm 0.3$ & $6.7 \pm 0.4$ & $6.8 \pm 0.4$ \\
Myocardial enzyme spectrum & & & \\
TNT-HS (pg/ml) & $48.7 \pm 3.6$ & $48.4 \pm 3.7$ & $48.8 \pm 4.1$ \\
CK (U/L) & $3780.0 \pm 121.5$ & $3785.3 \pm 127.1$ & $3791.4 \pm 125.8$ \\
LDH-L (U/L) & $7690.5 \pm 120.2$ & $7692.5 \pm 122.3$ & $7700.4 \pm 131.8$ \\
CK-MB (U/L) & $3770.9 \pm 86.3$ & $3782.7 \pm 103.4$ & $3792.9 \pm 115.1$ \\
Myo (ng/mL) & $72.9 \pm 2.9$ & $73.6 \pm 2.5$ & $73.9 \pm 3.5$ \\
\hline & & &
\end{tabular}

Data are mean $\pm S D(n=3)$.

As shown in Table 1, there were no alterations in blood urea nitrogen $(\mathrm{BUN})$ and creatinine $(\mathrm{Cr})$, indicating that PLT@ZrO2 did not result in kidney dysfunction. Due to tumor invasion and metastasis, alanine transaminase (ALT), and aspartate amino-transferase (AST) in the control group and $\mathrm{ZrO} 2$ group were significantly elevated, but levels in the PLT@ZrO2 group were normal, indirectly indicating that PLT@ZrO2 inhibited the liver invasion and metastasis of Hela cells. Indicators of cardiac function, such as Lactate dehydrogenase (LDH), hypersensitive troponin T (TNT-HS), creatinine kinase $(\mathrm{CK})$, creatinine kinase-MB (CK-MB), and myoglobin (Myo), were not elevated in the PLT@ ZrO2 group (Table 1). Histological images of heart, spleen, and kidney did not show abnormalities in both ZrO2 and PLT@ZrO2 groups (Figure 9). These results indicated that PLT@ZrO2 could inhibit the elevation of ALT and AST and exhibit fewer side effects.

\section{CONCLUSION}

In this study, we have shown PLT@ZrO2, a PLTm vesicleencapsulated $\mathrm{ZrO} 2$ nanocomposite, targeted subcutaneous and metastatic tumor sites, enhanced the anticancer effects of $\mathrm{ZrO} 2$, and inhibited tumor invasion and metastasis. $\mathrm{ZrO} 2 \mathrm{NPs}$ coated with PLTm vesicles escaped phagocytosis by immune cells, extended their retention, and targeted tumor sites. Additionally, we did not observe systemic toxicity after treatment with PLT@ZrO2. The PLT@ZrO2 nanocomposite has potential as a non-toxic and efficient targeted anticancer platform capable of inhibiting tumor growth, invasion and metastasis. 


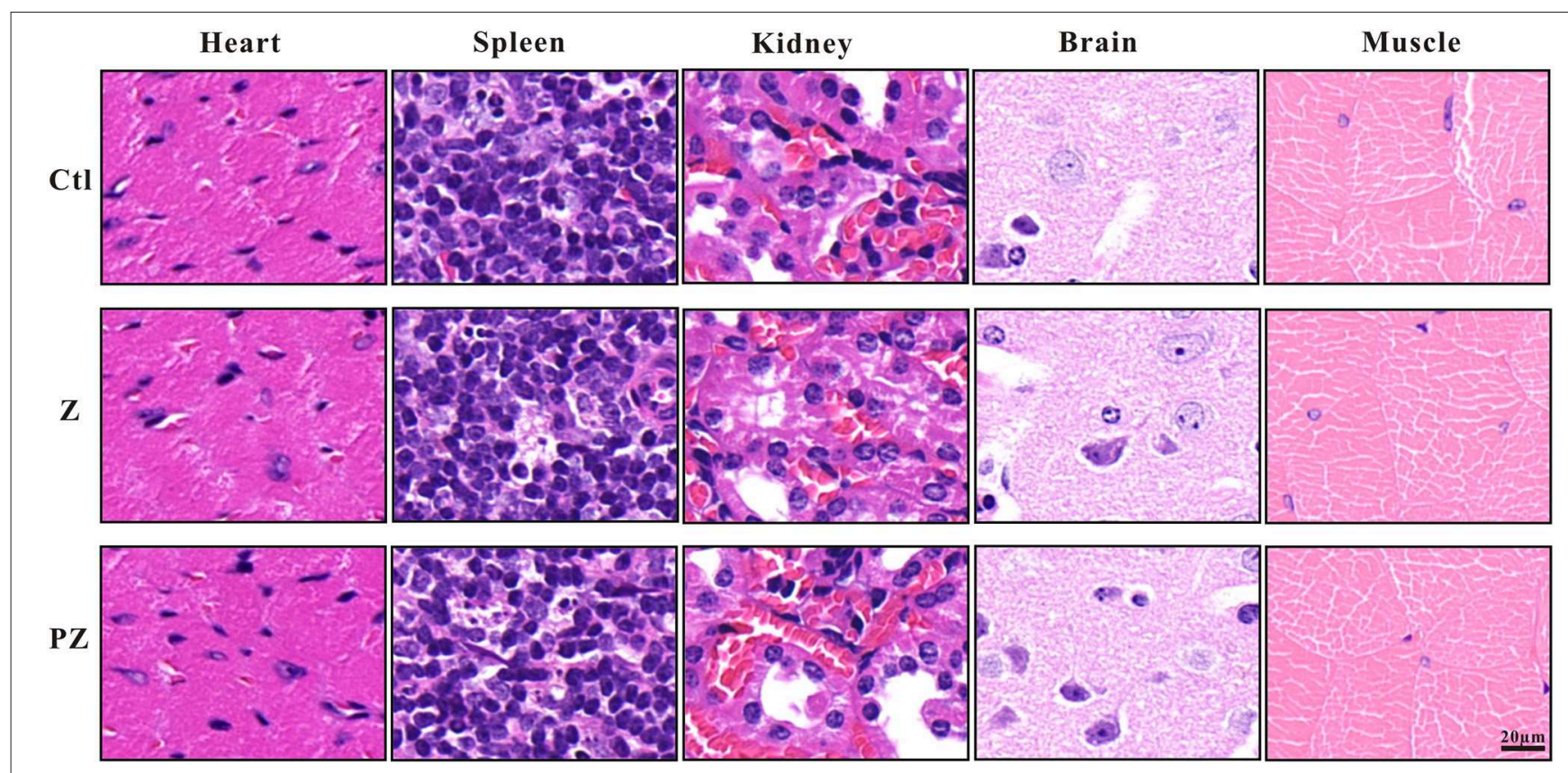

FIGURE 9 | Histological images of heart, spleen, kidney, brain and skeletal muscle after ZrO2 or PLT@ZrO2 treatment and HE staining. Ctl, Control; Z, ZrO2; PZ, PLT@ZrO2. Scale bar: $20 \mu \mathrm{m}$.

\section{DATA AVAILABILITY STATEMENT}

The original data supporting this article conclusions will be made available to any qualified researcher by the authors without reservation.

\section{ETHICS STATEMENT}

The ethics committee of Third Xiangya Hospital of Central South University (No. 2017-s75) approved the animal experiment, and the guidelines released by the Ministry of Science and Technology of the People's Republic of China in September 30th, 2006 guided the animal care.

\section{REFERENCES}

Alaseem, A., Alhazzani, K., Dondapati, P., Alobid, S., Bishayee, A., and Rathinavelu, A. (2019). Matrix metalloproteinases: a challenging paradigm of cancer management. Semin. Cancer Biol. 56, 100-115. doi: 10.1016/j.semcancer.2017.11.008

Al-Fahdawi, M. Q., Rasedee, A., Al-Qubaisi, M. S., Alhassan, F. H., Rosli, R., El Zowalaty, M. E., et al. (2015). Cytotoxicity and physicochemical characterization of iron-manganese-doped sulfated zirconia nanoparticles. Int. J. Nanomed. 10, 5739-5750. doi: 10.2147/IJN.S82586

Alves, C. C., Carneiro, F., Hoefler, H., and Becker, K. F. (2009). Role of the epithelial-mesenchymal transition regulator Slug in primary human cancers. Front. Biosci. 14, 3035-3050. doi: 10.2741/3433

Ansieau, S., Collin, G., and Hill, U. (2014). EMT or EMT-promoting transcription factors, where to focus the light? Front. Oncol. 4:353. doi: 10.3389/fonc. 2014.00353

Balaji, S., Mandal, B. K., Ranjan, S., Dasgupta, N., and Chidambaram, R. (2017). Nano-zirconia - evaluation of its antioxidant and anticancer

\section{AUTHOR CONTRIBUTIONS}

The manuscript was written through contributions of all authors. All authors have given approval to the final version of the manuscript.

\section{FUNDING}

This work was supported by the National Natural Science Foundations of China (Nos. 81971748, 81600461, 81602801), and the Graduate Self-Exploration and Innovation Project of Central South University of China under Grant (No. 2019zzts363).

activity. J. Photochem. Photobiol. B170, 125-133. doi: 10.1016/j.jphotobiol.2017. 04.004

Borsig, L., Wong, R., Feramisco, J., Nadeau, D. R., Varki, N. M., and Varki, A. (2001). Heparin and cancer revisited: mechanistic connections involving platelets, P-selectin, carcinoma mucins, and tumor metastasis. Proc. Natl. Acad. Sci. U.S.A. 98, 3352-3357. doi: 10.1073/pnas.061 615598

Celentano, A., Yap, T., Paolini, R., Yiannis, C., Mirams, M., Koo, K., et al. (2020). Inhibition of matrix metalloproteinase-2 modulates malignant behaviour of oral squamous cell carcinoma cells. J. Oral. Pathol. Med. doi: 10.1111/jop.12992. [Epub ahead of print].

Chazotte, B. (2011). Labeling nuclear DNA using DAPI. Cold Spring Harb. Protoc. 2011:pdb prot5556. doi: 10.1101/pdb.prot5556

Chen, Y. Q., Liu, B., Tang, D. G., and Honn, K. V. (1992). Fatty acid modulation of tumor cell-platelet-vessel wall interaction. Cancer Metastasis Rev. 11, 389-409. doi: 10.1007/BF01307189

Cheng, H. C., Abdel-Ghany, M., Elble, R. C., and Pauli, B. U. (1998). Lung endothelial dipeptidyl peptidase IV promotes adhesion and metastasis of rat 
breast cancer cells via tumor cell surface-associated fibronectin. J. Biol. Chem. 273, 24207-24215. doi: 10.1074/jbc.273.37.24207

Crowley, L. C., Marfell, B. J., and Waterhouse, N. J. (2016). Analyzing cell death by nuclear staining with hoechst 33342. Cold Spring Harb Protoc. 2016:pdb.prot087205. doi: 10.1101/pdb.prot087205

Gasic, G. J. (1984). Role of plasma, platelets, and endothelial cells in tumor metastasis. Cancer Metastasis Rev. 3, 99-114. doi: 10.1007/BF00047657

Goto, H., Kimmey, S. C., Row, R. H., Matus, D. Q., and Martin, B. L. (2017). FGF and canonical Wnt signaling cooperate to induce paraxial mesoderm from tailbud neuromesodermal progenitors through regulation of a twostep epithelial to mesenchymal transition. Development 144, 1412-1424. doi: $10.1242 /$ dev.143578

Grzegrzolka, J., Biala, M., Wojtyra, P., Kobierzycki, C., Olbromski, M., Gomulkiewicz, A., et al. (2015). Expression of EMT markers SLUG and TWIST in breast cancer. Anticancer Res. 35, 3961-3968.

Gugnoni, M., Sancisi, V., Manzotti, G., Gandolfi, G., and Ciarrocchi, A. (2016). Autophagy and epithelial-mesenchymal transition: an intricate interplay in cancer. Cell Death Dis. 7:e2520. doi: 10.1038/cddis.2016.415

Gupta, G. P., and Massagué, J. (2006). Cancer metastasis: building a framework. Cell 127, 679-695. doi: 10.1016/j.cell.2006.11.001

Hao, L., Ha, J. R., Kuzel, P., Garcia, E., and Persad, S. (2012). Cadherin switch from E- to N-cadherin in melanoma progression is regulated by the PI3K/PTEN pathway through Twist and Snail. Br. J. Dermatol. 166, 1184-1197. doi: $10.1111 / j .1365-2133.2012 .10824 . x$

Honn, K. V., and Tang, D. (1992b). Hemostasis and malignancy: an overview. Cancer Metastasis Rev. 11, 223-226. doi: 10.1007/BF01307178

Honn, K. V., and Tang, D. G. (1992a). Adhesion molecules and tumor cell interaction with endothelium and subendothelial matrix. Cancer Metastasis Rev. 11, 353-375. doi: 10.1007/BF01307187

Hotz, B., Arndt, M., Dullat, S., Bhargava, S., Buhr, H. J., and Hotz, H. G. (2007). Epithelial to mesenchymal transition: expression of the regulators snail, slug, and twist in pancreatic cancer. Clin. Cancer Res. 13, 4769-4776. doi: 10.1158/1078-0432.CCR-06-2926

Hseu, Y. C., Lin, Y. C., Rajendran, P., Thigarajan, V., Mathew, D. C., Lin, K. Y., et al. (2019). Antrodia salmonea suppresses invasion and metastasis in triple-negative breast cancer cells by reversing EMT through the NF-kappaB and Wnt/beta-catenin signaling pathway. Food Chem. Toxicol. 124, 219-230. doi: 10.1016/j.fct.2018.12.009

Hu, C. M., Fang, R. H., Wang, K. C., Luk, B. T., Thamphiwatana, S., Dehaini, D., et al. (2015b). Nanoparticle biointerfacing by platelet membrane cloaking. Nature 526, 118-121. doi: 10.1038/nature15373

Hu, Q., Sun, W., Qian, C., Wang, C., Bomba, H. N., and Gu, Z. (2015a). Anticancer platelet-mimicking nanovehicles. Adv Mater. 27, 7043-7050. doi: 10.1002/adma.201503323

Huang, L., Cheng, H. C., Isom, R., Chen, C. S., Levine, R. A., and Pauli, B. U. (2008). Protein kinase cepsilon mediates polymeric fibronectin assembly on the surface of blood-borne rat breast cancer cells to promote pulmonary metastasis. J. Biol. Chem. 283, 7616-7627. doi: 10.1074/jbc.M705839200

Huber, M. A., Kraut, N., and Beug, H. (2005). Molecular requirements for epithelial-mesenchymal transition during tumor progression. Curr. Opin. Cell Biol. 17, 548-558. doi: 10.1016/j.ceb.2005.08.001

Ivaska, J., Pallari, H. M., Nevo, J., and Eriksson, J. E. (2007). Novel functions of vimentin in cell adhesion, migration, and signaling. Exp Cell Res. 313, 2050-2062. doi: 10.1016/j.yexcr.2007.03.040

Jang, Y. Y., Cho, D., Kim, S. K., Shin, D. J., Park, M. H., Lee, J. J., et al. (2012). An improved flow cytometry-based natural killer cytotoxicity assay involving calcein AM staining of effector cells. Ann. Clin. Lab. Sci. 42, 42-49.

Karpatkin, S., and Pearlstein, E. (1981). Role of platelets in tumor cell metastases. Ann. Intern. Med. 95, 636-641. doi: 10.7326/0003-4819-95-5-636

Knowles, L. M., Gurski, L. A., Maranchie, J. K., and Pilch, J. (2015). Fibronectin matrix formation is a prerequisite for colonization of kidney tumor cells in fibrin. J. Cancer 6, 98-104. doi: 10.7150/jca.10496

Kumar, S., Sharma, J. G., Maji, S., and Malhotra, B. D. (2016). Nanostructured zirconia decorated reduced graphene oxide based efficient biosensing platform for non-invasive oral cancer detection. Biosens. Bioelectron. 78, 497-504. doi: 10.1016/j.bios.2015.11.084

Kwak, H. I., Kang, H., Dave, J. M., Mendoza, E. A., Su, S. C., Maxwell, S. A., et al. (2012). Calpain-mediated vimentin cleavage occurs upstream of MT1-MMP membrane translocation to facilitate endothelial sprout initiation. Angiogenesis 15, 287-303. doi: 10.1007/s10456-012-9262-4

Lengyel, E., Schmalfeldt, B., Konik, E., Späthe, K., Härting, K., Fenn, A., et al. (2001). Expression of latent matrix metalloproteinase 9 (MMP-9) predicts survival in advanced ovarian cancer. Gynecol. Oncol. 82, 291-298. doi: 10.1006/gyno.2001.6243

$\mathrm{Li}, \mathrm{H} ., \mathrm{Wu}, \mathrm{X}$, and Cheng, X. (2016). Advances in diagnosis and treatment of metastatic cervical cancer. J. Gynecol. Oncol. 27:e43. doi: 10.3802 /jgo.2016.27.e43

Li, X. Y., Ban, G. F., Al-Shameri, B., He, X., Liang, D. Z., and Chen, W. X. (2018). High-temperature requirement protein A1 regulates odontoblastic differentiation of dental pulp cells via the transforming growth factor beta 1/smad signaling pathway. J. Endod. 44, 765-772. doi: 10.1016/j.joen.2018.02.003

Liu, C. C., Cai, D. L., Sun, F., Wu, Z. H., Yue, B., Zhao, S. L., et al. (2017). FERMT1 mediates epithelial-mesenchymal transition to promote colon cancer metastasis via modulation of beta-catenin transcriptional activity. Oncogene 36, 1779-1792. doi: 10.1038/onc.2016.339

Liu, Y., Qian, J., Li, X., Chen, W., Xu, A., Zhao, K., et al. (2016). Long noncoding RNA BX357664 regulates cell proliferation and epithelial-to-mesenchymal transition via inhibition of TGF-beta1/p38/HSP27 signaling in renal cell carcinoma. Oncotarget 7, 81410-81422. doi: 10.18632/oncotarget.12937

Mftah, A., Alhassan, F. H., Al-Qubaisi, M. S., El Zowalaty, M. E., Webster, T. J., Sh-Eldin, M., et al. (2015). Physicochemical properties, cytotoxicity, and antimicrobial activity of sulphated zirconia nanoparticles. Int. J. Nanomed. 10 765-774. doi: 10.2147/IJN.S66058

Mrozik, K. M., Blaschuk, O. W., Cheong, C. M., Zannettino, A. C. W., and Vandyke, K. (2018). N-cadherin in cancer metastasis, its emerging role in haematological malignancies and potential as a therapeutic target in cancer. BMC Cancer 18:939. doi: 10.1186/s12885-018-4845-0

Nabeshima, K., Inoue, T., Shimao, Y., and Sameshima, T. (2002). Matrix metalloproteinases in tumor invasion: role for cell migration. Pathol. Int. 52 , 255-264. doi: 10.1046/j.1440-1827.2002.01343.x

Nakajima, S., Doi, R., Toyoda, E., Tsuji, S., Wada, M., Koizumi, M., et al. (2004). N-cadherin expression and epithelial-mesenchymal transition in pancreatic carcinoma. Clin. Cancer Res. $10(12 \mathrm{Pt} 1), 4125-4133$. doi: 10.1158/1078-0432.CCR-0578-03

Nieswandt, B., Hafner, M., Echtenacher, B., and Männel, D. N. (1999). Lysis of tumor cells by natural killer cells in mice is impeded by platelets. Cancer Res. 59, 1295-1300.

Nieszporek, A., Skrzypek, K., Adamek, G., and Majka, M. (2019). Molecular mechanisms of epithelial to mesenchymal transition in tumor metastasis. Acta Biochim. Pol. 66, 509-520. doi: 10.18388/abp.2019_2899

Onder, T. T., Gupta, P. B., Mani, S. A., Yang, J., Lander, E. S., and Weinberg, R. A. (2008). Loss of E-cadherin promotes metastasis via multiple downstream transcriptional pathways. Cancer Res. 68, 3645-3654. doi: 10.1158/0008-5472.CAN-07-2938

Peng, L., Yuan, X., Jiang, B., Tang, Z., and Li, G. C. (2016). LncRNAs: key players and novel insights into cervical cancer. Tumour Biol. 37, 2779-2788. doi: 10.1007/s13277-015-4663-9

Puisieux, A., Brabletz, T., and Caramel, J. (2014). Oncogenic roles of EMT-inducing transcription factors. Nat. Cell Biol. 16, 488-494. doi: $10.1038 /$ ncb2976

Roomi, M. W., Monterrey, J. C., Kalinovsky, T., Rath, M., and Niedzwiecki, A. (2010). In vitro modulation of MMP-2 and MMP-9 in human cervical and ovarian cancer cell lines by cytokines, inducers and inhibitors. Oncol Rep. 23, 605-614. doi: 10.3892/or_00000675

Sabrkhany, S., Kuijpers, M. J. E., Knol, J. C., Olde Damink, S. W. M., Dingemans, A. C., Verheul, H. M., et al. (2018). Exploration of the platelet proteome in patients with early-stage cancer. J. Proteom. 177, 65-74. doi: 10.1016/j.jprot.2018.02.011

Shang, Y., Wang, Q., Wu, B., Zhao, Q., Li, J., Huang, X., et al. (2019). Plateletmembrane-camouflaged black phosphorus quantum dots enhance anticancer effect mediated by apoptosis and autophagy. ACS Appl. Mater. Interf. 11, 28254-28266. doi: 10.1021/acsami.9b04735

Shen, C. J., Chan, S. H., Lee, C. T., Huang, W. C., Tsai, J. P., and Chen, B. K. (2017). Oleic acid-induced ANGPTL4 enhances head and neck squamous cell carcinoma anoikis resistance and metastasis via up-regulation of fibronectin. Cancer Lett. 386, 110-122. doi: 10.1016/j.canlet.2016.11.012 
Shi, F., Harman, J., Fujiwara, K., and Sottile, J. (2010). Collagen I matrix turnover is regulated by fibronectin polymerization. Am. J. Physiol. Cell Physiol. 298, C1265-1275. doi: 10.1152/ajpcell.00341.2009

Shu, J., Wang, L., Han, F., Chen, Y., Wang, S., and Luo, F. (2019). BTBD7 downregulates E-cadherin and promotes epithelial-mesenchymal transition in lung cancer. Biomed. Res. Int. 2019:5937635. doi: 10.1155/2019/5937635

Sun, L., and Fang, S. (2016). Epigenetic regulation of epithelial-mesenchymal transition. Cell Mol. Life Sci. 73, 4493-4515. doi: 10.1007/s00018-016-2303-1

Tanaka, N. G., Tohgo, A., and Ogawa, H. (1986). Platelet-aggregating activities of metastasizing tumor cells. V. In situ roles of platelets in hematogenous metastases. Invasion Metastasis 6, 209-224.

Thiery, J. P., Acloque, H., Huang, R. Y., and Nieto, M. A. (2009). Epithelialmesenchymal transitions in development and disease. Cell 139, 871-890. doi: 10.1016/j.cell.2009.11.007

Tiwari, N., Tiwari, V. K., Waldmeier, L., Balwierz, P. J., Arnold, P., Pachkov, M., et al. (2013). Sox4 is a master regulator of epithelial-mesenchymal transition by controlling Ezh2 expression and epigenetic reprogramming. Cancer Cell 23, 768-783. doi: 10.1016/j.ccr.2013.04.020

van Zijl, F., Zulehner, G., Petz, M., Schneller, D., Kornauth, C., Hau, M., et al. (2009). Epithelial-mesenchymal transition in hepatocellular carcinoma. Future Oncol. 5, 1169-1179. doi: 10.2217/fon.09.91

Venu, M., Venkateswarlu, S., Reddy, Y. V. M., Seshadri Reddy, A., Gupta, V. K., Yoon, M., et al. (2018). Highly sensitive electrochemical sensor for anticancer drug by a zirconia nanoparticle-decorated reduced graphene oxide nanocomposite. ACS Omega 3, 14597-14605. doi: 10.1021/acsomega.8b02129

Virtakoivu, R., Mai, A., Mattila, E., De Franceschi, N., Imanishi, S. Y., Corthals, G., et al. (2015). Vimentin-ERK signaling uncouples slug gene regulatory function.
Cancer Res. 75, 2349-2362. doi: 10.1158/0008-5472.CAN-14-2842

Wang, S. P., Wang, W. L., Chang, Y. L., Wu, C. T., Chao, Y. C., Kao, S. H., et al. (2009). p53 controls cancer cell invasion by inducing the MDM2-mediated degradation of Slug. Nat. Cell Biol. 11, 694-704. doi: 10.1038/ncb1875

Watson-Hurst, K., and Becker, D. (2006). The role of N-cadherin, MCAM and beta3 integrin in melanoma progression, proliferation, migration and invasion. Cancer Biol. Ther. 5, 1375-1382. doi: 10.4161/cbt.5.10.3241

Yang, Y., Wang, Z., Yang, M., Li, J., Zheng, F., Shen, G., et al. (2007). Electrical detection of deoxyribonucleic acid hybridization based on carbonnanotubes/nano zirconium dioxide/chitosan-modified electrodes. Analyt. Chim. Acta 584, 268-274. doi: 10.1016/j.aca.2006.11.055

Zhou, Q., Abraham, A. D., Li, L., Babalmorad, A., Bagby, S., Arcaroli, J. J., et al. (2016). Topoisomerase IIalpha mediates TCF-dependent epithelialmesenchymal transition in colon cancer. Oncogene 35, 4990-4999. doi: $10.1038 /$ onc.2016.29

Conflict of Interest: The authors declare that the research was conducted in the absence of any commercial or financial relationships that could be construed as a potential conflict of interest.

Copyright (C) 2020 Shang, Wang, Li, Zhao, Huang, Dong, Liu, Gui and Nie. This is an open-access article distributed under the terms of the Creative Commons Attribution License (CC BY). The use, distribution or reproduction in other forums is permitted, provided the original author(s) and the copyright owner(s) are credited and that the original publication in this journal is cited, in accordance with accepted academic practice. No use, distribution or reproduction is permitted which does not comply with these terms. 